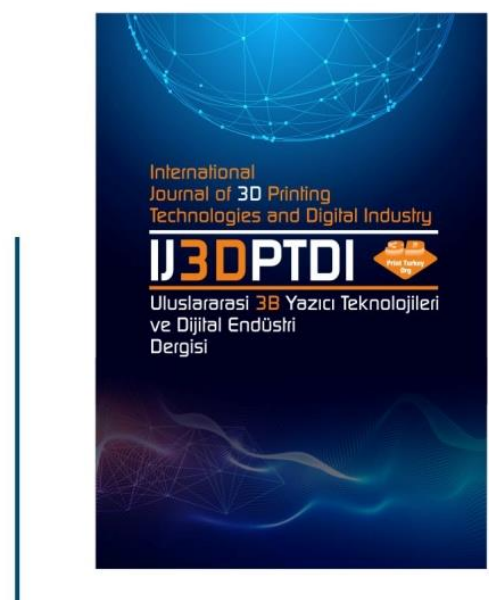

ULUSLARARASI 3B YAZICI TEKNOLOJILERI

VE DIJITAL ENDÜSTRI DERGISI

INTERNATIONAL JQURNAL QF 30 PRINTING TECHNOLOGIES AND DIGITAL INDUSTRY

ISSN:2602-3350 [Online]

URL: https://dergipark.org.tr/ij3dptdi

\title{
STRENGTHENING EFFECT OF FLOODING IN 3D PRINTED POROUS SOFT ROBOTICS SCAFFOLDS
}

Yazarlar (Authors): Ozgun Selvi®*, Onat Halis Totuk ${ }^{\circledR}$, Selcuk Mistikoglu@, Ozan Arslan (1)

Bu makaleye şu şekilde atıfta bulunabilirsiniz (To cite to this article): Selvi O., Totuk O.H., Mistikoglu S., Arslan O. "Strengthening Effect of Flooding in 3D Printed Porous Soft Robotics Scaffolds" Int. J. of 3D Printing Tech. Dig. Ind., 5(2): 293-301, (2021). 


\title{
STRENGTHENING EFFECT OF FLOODING IN 3D PRINTED POROUS SOFT ROBOTICS SCAFFOLDS
}

\author{
Ozgun Selvi ${ }^{\text {a }}$ **, Onat Halis Totuk ${ }^{\text {a,b }}$ iD , Selcuk Mistikoglu ${ }^{\text {iD }}$, Ozan Arslan ${ }^{a}$ iD \\ ${ }^{a}$ Çankaya University, Engineering Faculty, Mechanical Engineering Department, TURKEY \\ ' Iskenderun Technical University, Engineering Faculty, Mechanical Engineering Department, TURKEY \\ *Corresponding Author: ozgunselvi@cankaya.edu.tr
}

(Received: 08.06.2021; Revised: 16.07.2021; Accepted: 28.08.2021)

\begin{abstract}
This study aims to design and 3D print porous elements for soft robotic applications and test the stiffness changes when the cavities are filled with liquids. When an elastic element has porous scaffolds, the stiffness can be controlled by filling the cavities with a liquid. A gyroid structure is selected for the design and evaluation of the characteristics of elements. The stiffness of the element in both non-filled and liquid-filled modes is analyzed using Finite Element Model (FEM) simulation Software in two modes where simple support with central loading and compressive uniform loading. A porous test structure is created and tested in these modes for observation of the stiffness change. In this project, employing a Fused Deposition Modelling (FDM) printer enabled us to make our thoughts into reality. The results show that liquid-filling can be used as a stiffening method for porous scaffolds in soft robotic applications.
\end{abstract}

Keywords: Soft Robotic. Flexible Filament. Porous. Stiffness. 3D Printing.

\section{INTRODUCTION}

3D printing is one of the fast-developing and trending topics in the science area. Among the seven methods of Additive Manufacturing, Fused Deposition Modelling (FDM) can be used to produce Computer-Aided Designed (CAD) parts by combining melted plastics layer by layer. Using 3D printing, many different parts can be produced from plastics with shore values around A65 to obtain desired softness.

Soft robotics applications are a proliferous topic among 3D printer researchers [1-3]. Soft robotics uses soft plastic filaments for producing robots with the capability of elastic transformability [4]. Scientists also use biomimetic science for developing the motioning and sensing ability of soft robots [5-10]. Totuk et al. [11] studied biomimetic, and they mentioned that bio-inspired additive manufacturing leveled up and became 4D printing. Owing the development of biomimetic and 3D printing technologies, robots have become more compatible with human-robot interactions [12-15]. Wang et al. [16] designed a soft mechanical grasper as part of these interactions. Besides, Selvi et al. [17] conduct an experiment for observing the usage ability of 3 different shapes as soft actuators or sensors. Moreover, Donatelli et al. [18] produced a caterpillar-like soft robot by using biomimetic techniques. On the other hand, soft robots have some possible problems, like preserving the shape during motions and unpredictable motion behavior of soft materials.

Scientists generally use foam structures to provide flexible structures without losing the robustness of soft plastic materials. Having wild numbers of different application chances, porous structures are often used on soft robotic research projects [19-28]. Porous foam structures act as flex as sponges; also, they can fill with liquids for enhancing stiffness and robustness [29, 30]. Although liquid filling can improve the stiffness of soft robotic parts, it can also change the elastic properties of the part. Therefore, Liu et al. [31] researched the effect of liquid filling on the elastic properties of porous materials. This critical work found that elastic properties change with liquid filling, and it directly depended on factors like liquid pressure and pore scales. Gyroid shape infill is one of the best suiting solutions for generating 
porous structures. Gyroid shape provides both flexibility and porous structure simultaneously, filling liquids into the structure for changing stiffness [32-34].

Abueidda et al. [35] studied the mechanical properties of gyroid structures and made experimental and finite element studies. As a result, they found that the compressive strength of gyroid structures is one of the best compared to the other.

Varying stiffness is a rising topic in soft robotics studies [36-41]. Stiffness is an essential topic for enhancing the quality and safety of soft robotic applications [42]. Liquid filling operations and using different production materials are used to ensure the variety of stiffness for different situations [43-48]. The idea of observing the change in stiffness with the Liquid filling is the inspiration and motivation point of this study.

This study aims that, observing the strengthening effect of flooding in 3D printed porous soft robotics scaffolds. Two types of designs and two tests, which are associated with part types, were planned. Parts were 3D printed using shore A65 flexible filament, and FEM is used to analyze the parts. Results were obtained on Autodesk Inventor 2021 and discussed.

\section{MATERIAL AND METHOD}

The study observes stiffness change under pressure force and bending force by filling the part with the liquid. 3D designs of parts were created initially, and soft filament for 3D printing was selected. Parts were modeled to maximize the bending angle on the bending test and volume change in the pressure test and minimize required loads for conducting tests. Shore A65 filament, thermoplastic polyurethane, was selected for printing part due to its high flexibility capacity. Two types of soft parts were printed with the gyroid infill for two kinds of tests. Gyroid infill provides scaffold structure that was necessary for the experiment. Gyroid infill was represented in Figure 1a and Figure 1b.

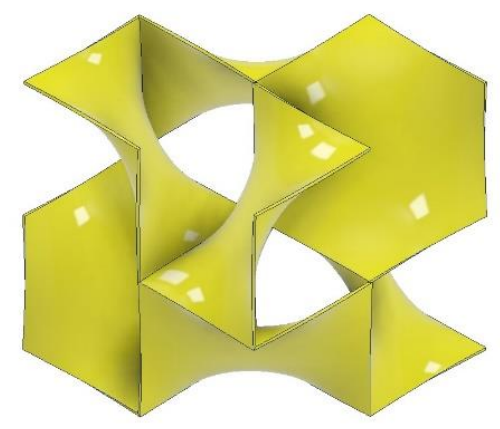

(a)

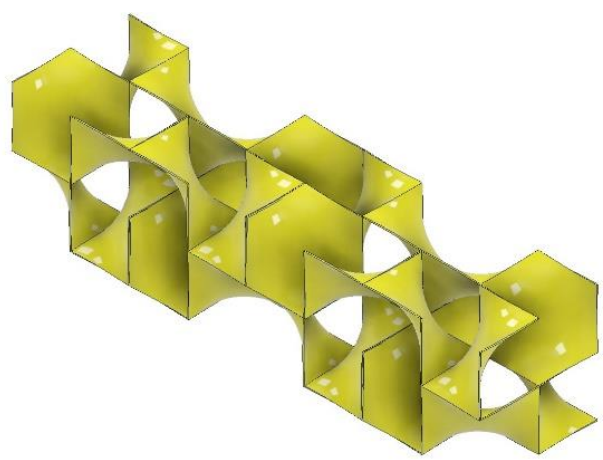

(b)

Figure 1. Figures of gyroid infill: (a) Single gyroid section and (b) Complete gyroid infill.

The rectangular prism-shaped part, presented in Figures $2 \mathrm{a}$ and $2 \mathrm{~b}$, was printed for the bending test, and the cylindrical-shaped part, shown in Figure 2c, for the pressure test. In the printing phase, the bed temperature was set to $60^{\circ} \mathrm{C}$, and the nozzle temperature was set to $215^{\circ} \mathrm{C}$. Layer thickness and nozzle diameter were selected as $0.2 \mathrm{~mm}$ and $0.4 \mathrm{~mm}$, respectively. Finite element analyses were made with Autodesk Inventor Professional 2021. Non-linear finite element model was selected. Other papers were analyzed and used on deciding to model type. Zhang et al. conducted research that "Estimating the effective Young's modulus of soft tissues from indentation tests - nonlinear finite element analysis of effects of friction and large deformation" [49]. The research was used in deciding phase. Results of the analysis were obtained and discussed. 


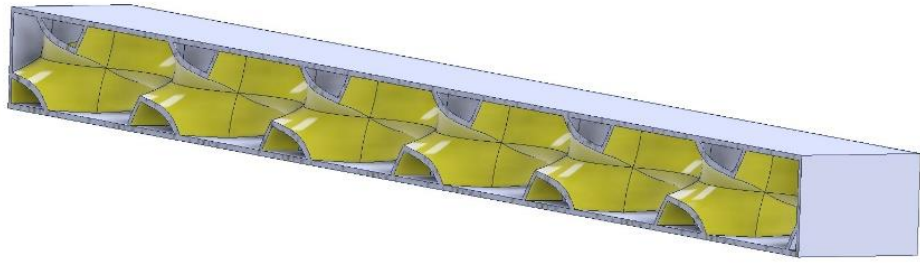

(a)

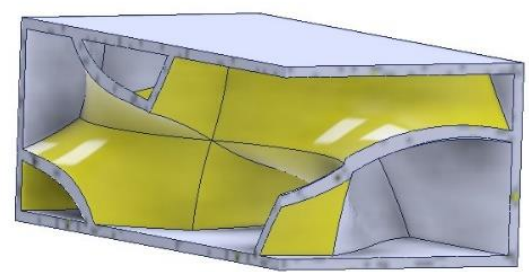

(b)

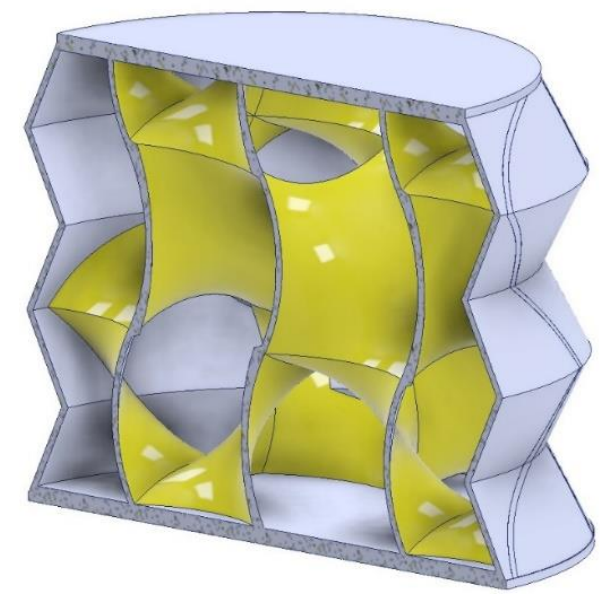

(c)

Figure 2. Figures of rectangular prism gyroid infill: (a) Half section view of rectangular prism (b) Quarter section view of the rectangular prism (c) Gyroid infill of the cylindrical-shaped part.

\subsection{Bending Test}

A rectangular prism-shaped beam was printed, and after an impermeability check, it was used to implement a bending test. The test was held by hanging $100 \mathrm{gr}$ weights to be $1100 \mathrm{gr}$ in total. Water was used as a filling Liquid, and it was applied by syringe. The test setup was presented below as Figure 3a no liquid applied test stage and Figure $3 \mathrm{~b}$ liquid applied.

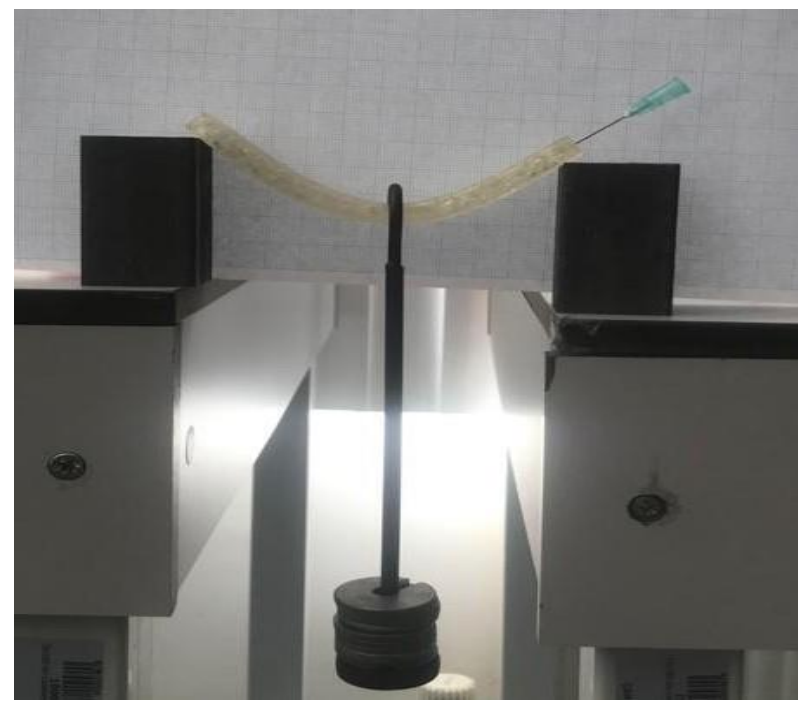

(a)

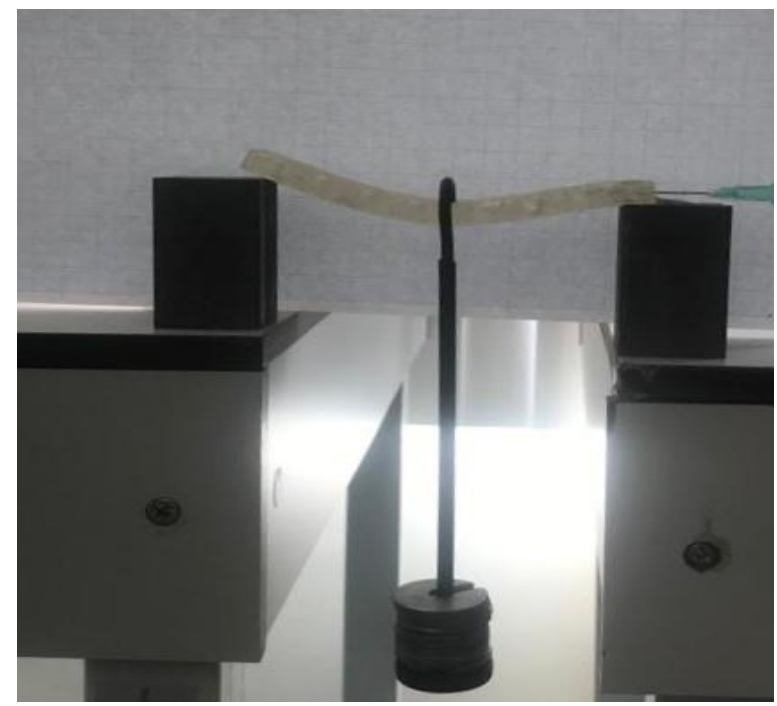

(b)

Figure 3. Figures of bending test: (a) No liquid applied test stage and (b) Liquid applied test stage. 


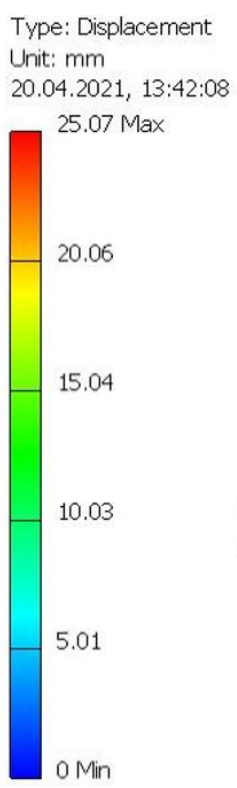

Type: Displacement Unit: $\mathrm{mm}$

$20.04 .2021,13: 45: 00$

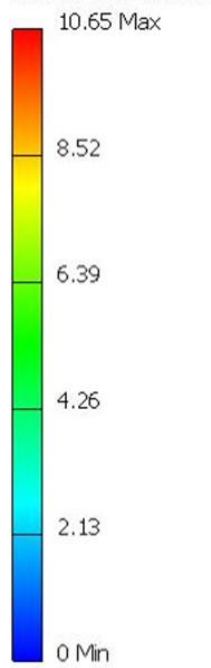

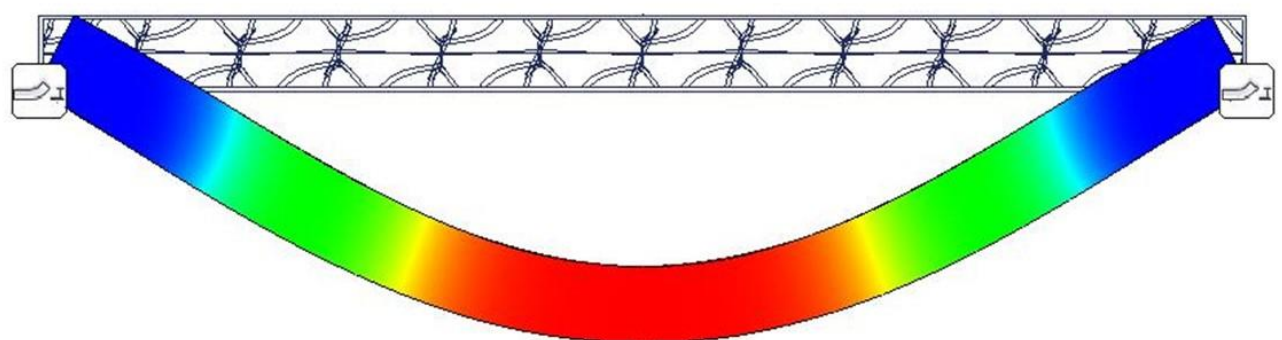

(a)

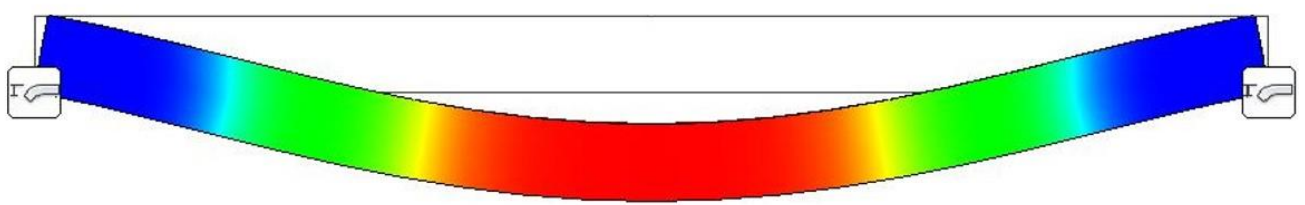

(b)

Figure 4. Figures of Finite Element Analysis (FEA) for bending test: (a) FEA of no liquid applied stage and (b) FEA of the liquid applied stage.

\subsection{Pressure Test}

The cylindrical-shaped part was used for the pressure test, and bellows were added along the side face of the cylinder to provide flexibility and support volume change without harming the thin sidewalls of the 3D printed soft part. An impermeability check for the liquid filling was made to part, and hereupon part was used to implement the pressure test. The test was held by putting 2000 gr weight as one solid part. Tap water was used as a filling Liquid, and it was applied by syringe. Setup for the test can be found below as Figure 5a no liquid applied test stage and Figure 5b liquid applied test stage. 


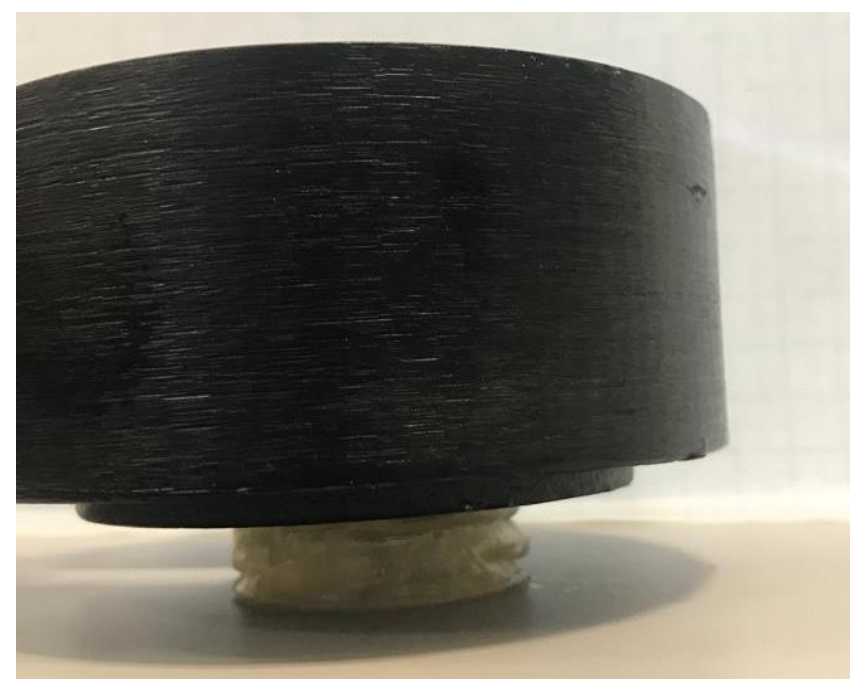

(a)

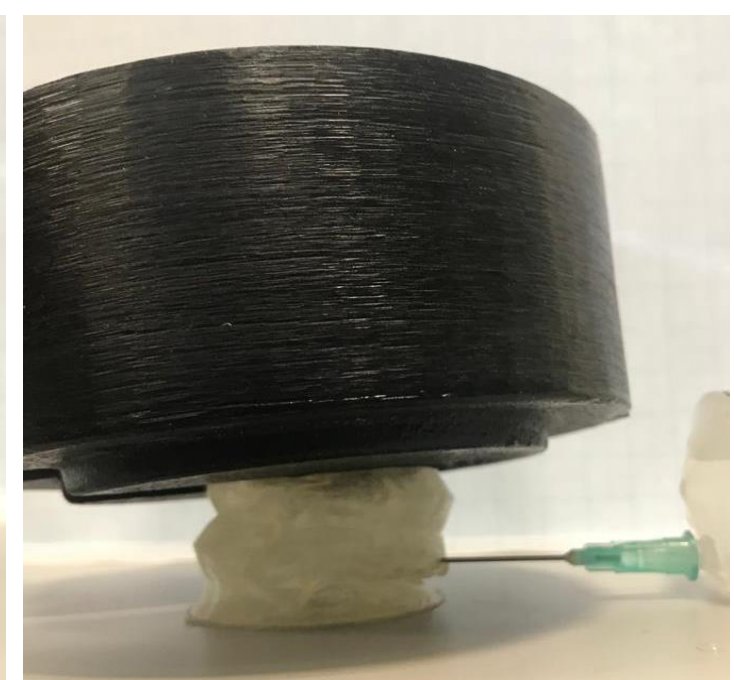

(b)

Figure 5. Figures of pressure test: (a) No liquid applied test stage and (b) Liquid applied test stage.

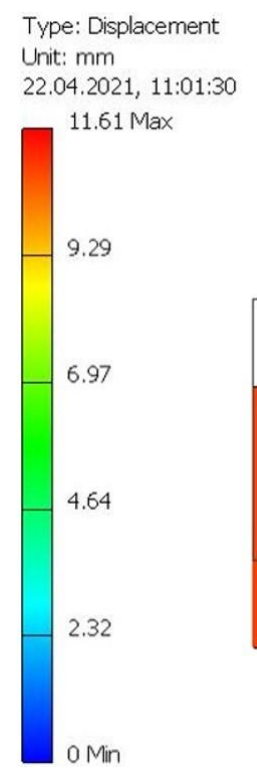

Type: Displacement

Unit: $\mathrm{mm}$

22.04.2021, 11:33:33

$3.244 \mathrm{Max}$

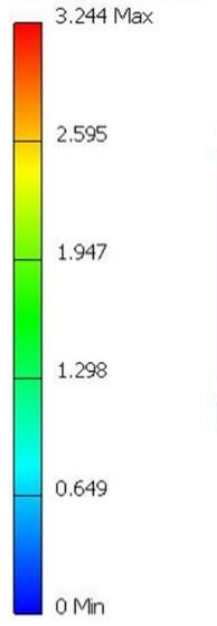

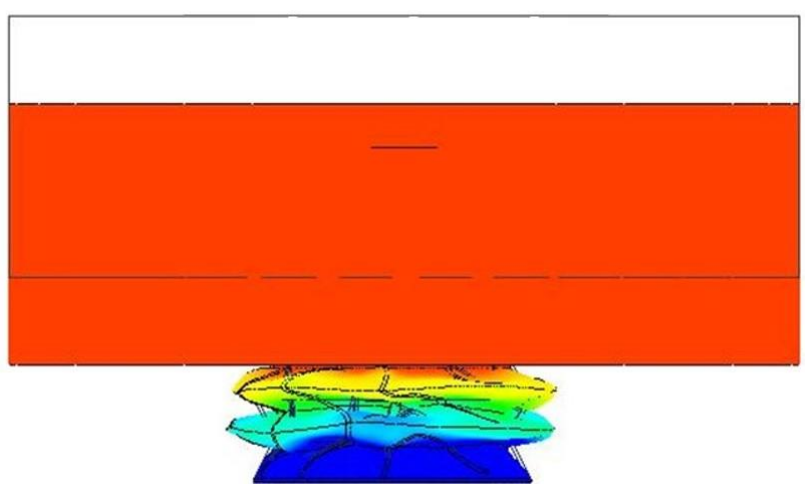

(a)

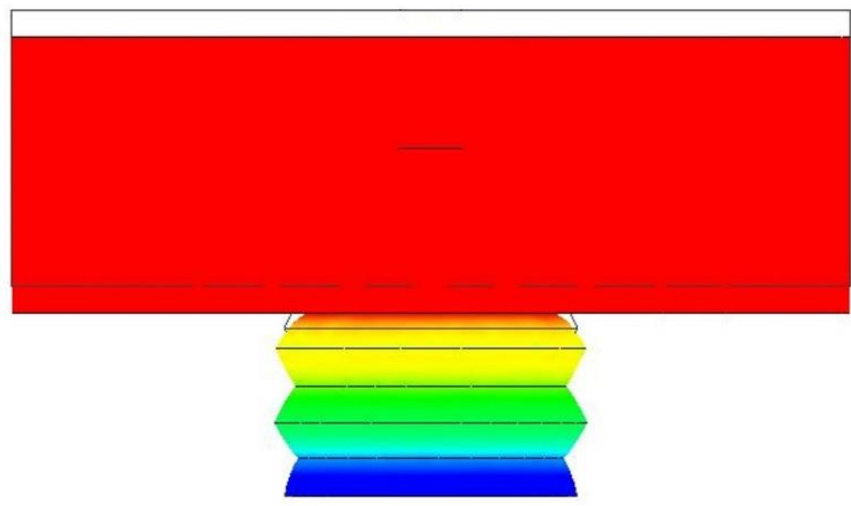

(b)

Figure 6. Figures of FEA for pressure test: (a) FEA of no liquid applied stage and (b) FEA of liquid applied stage. 


\section{RESULTS}

The results obtained from the bending experiment, shown in Figures $3 a$ and $3 b$, and from Finite Element Analysis (FEA), shown in Figures $4 \mathrm{a}$ and $4 \mathrm{~b}$, can be compared to understand the experiment's accuracy. The comparison indicates that bending FEA results have $25.07 \mathrm{~mm}$ displacement on no liquid filled the loaded and experimental results with $25.53 \mathrm{~mm}$ displacement. The liquid-filled loaded stage result for FEA is 10.65 , while the experimental result is $10.89 \mathrm{~mm}$. Besides, a similar implication can be made for pressure test results. Non-filled stage results for pressure test is $\mathrm{mm} 11.35$ while the result of FEA is $11.61 \mathrm{~mm}$. The liquid-filled result for the test setup is $3.17 \mathrm{~mm}$, while the FEA result is $3.24 \mathrm{~mm}$. According to bending test results, change on height over part length for no liquid loaded stage and liquidfilled loaded stage can be calculated as $21.28 \%$ and $9.08 \%$, respectively. In comparison, FEA results give $20.89 \%$ for no liquid loaded set and $8.88 \%$ for the liquid-filled loaded stage.

Moreover, displacement over height ratio can be calculated for no liquid loaded stage as $37,83 \%$, and liquid-filled loaded stage as $10,57 \%$ for pressure test. Moreover, FEA results percentages can be found as $38,70 \%$ for no liquid loaded stage and $10,80 \%$ liquid-filled loaded stage. Accuracy of percentage results proves that soft robotics elements' stiffness can have improved by applying liquids inside the porous structure. On the other hand, printing parameters should be optimized for enhancing the quality and impermeability of the gyroid structure.

\section{CONCLUSION}

This study set out to assess the possibility of strengthening the effect of flooding in 3D printed porous soft robotics scaffolds. Two designs were examined on two different test setups organized specially for each of the parts. When results were compared with the literature, it is found that Yamada et al. provided a bending motion on the sponge-like structure [50]. Their structure was made out of foam, and the motion was provided by vacuuming air, which is also fluid like our filler. A similar bending motion was observed, except that the strengthening effect was not examined. Moreover, Chen et al. created a spongelike structure from hyperelastic silicone foam to enhance the capacity of volume change [51]. Their compression ratio is similar to our gyroid-shaped model and proofs its validity. Again, no strengthening effect was examined, so a comparison could not have been made on that factor. In addition, Argiolas et al. conducted a similar experiment to ours [52]. They were used air as fluid and observed the strengthening effect by hanging weights to the part. Similar results were observed. Air improved the strength of the bent arm, and weight was carried due to this strengthening effect.

Findings are planned to strengthen soft robotics elements for enhancing the safety and quality of humanrobot interactions. 3D printing parameters enhancement, experiments with different shapes and liquids can be accepted as future work on this topic. Moreover, different infill percentages and different gyroid types would change the strengthening results.

\section{ACKNOWLEDGEMENT}

We sincerely thank İbrahim Ekici, a student of the Çankaya University Mechatronics Engineering Department, who has made an essential contribution to the 3D printing of the test parts.

\section{REFERENCES}

1. Wallin, T. J., Pikul, J., Shepherd, R. F., "3D printing of soft robotic systems", Nature Reviews Materials, Vol. 3, Pages 84-100, 2018.

2. Polygerinos, P., Correll, N., Morin, S. A., Mosadegh, B., Onal, C. D., Petersen, K., Cianchetti, M., Tolley, M. T., Shepherd, R. F., "Soft Robotics: Review of Fluid-Driven Intrinsically Soft Devices; Manufacturing, Sensing, Control, and Applications in Human-Robot Interaction", Advanced Engineering Materials, Vol. 19, Pages 1700016, 2017.

3. Yap, Y. L., Sing, S. L., Yeong, W. Y., "A review of 3D printing processes and materials for soft robotics", Rapid Prototyping Journal, Vol. 26, Pages 1345-1361, 2020.

4. Gorissen, B., Reynaerts, D., Konishi, S., Yoshida, K., Kim, J.-W., De Volder, M., "Elastic Inflatable Actuators for Soft Robotic Applications", Advanced Materials, Vol. 29, Pages 1604977, 2017. 
5. Stilli, A., Althoefer, K., Wurdemann, H. A., "Soft robotics. Bio-inspired antagonistic stiffening”, in Biosystems and Biorobotics, Pages 207-214, 2018.

6. Coyle, S., Majidi, C., LeDuc, P., Hsia, K. J., "Bio-inspired soft robotics: Material selection, actuation, and design”, Extreme Mechanics Letters, Vol. 22, Pages 51-59, 2018.

7. Kim, S., Laschi, C., Trimmer, B., "Soft robotics: a bioinspired evolution in robotics", Trends in Biotechnology, Vol. 31, Pages 287-294, 2013.

8. Podroužek, J., Marcon, M., Ninčević, K., Wan-Wendner, R., "Bio-inspired 3D infill patterns for additive manufacturing and structural applications", Materials, Vol. 12, Pages 1-12, 2019.

9. Bastola, A. K., Rodriguez, N., Behl, M., Soffiatti, P., Rowe, N. P., Lendlein, A., “Cactus-inspired design principles for soft robotics based on 3D printed hydrogel-elastomer systems”, Materials \& Design, Vol. 202, Pages 109515, 2021.

10. Li, S., Bai, H., Shepherd, R. F., Zhao, H., "Bio-inspired Design and Additive Manufacturing of Soft Materials, Machines, Robots, and Haptic Interfaces”, Angewandte Chemie International Edition, Vol. 58, Pages 11182-11204, 2019

11. Totuk, O. H., Başak, H., "Biyomimetik Eklemeli İmalat: 4B Basım”, in 2. International Symposium on Industrial Design and Engineering-ISIDE 2017, 2017.

12. Runciman, M., Darzi, A., Mylonas, G. P., "Soft Robotics in Minimally Invasive Surgery", Soft Robotics, Vol. 6, Pages 423-443, 2019.

13. Arata, J., Fujisawa, Y., Nakadate, R., Kiguchi, K., Harada, K., Mitsuishi, M., Hashizume, M., "Compliant four degree-of-freedom manipulator with locally deformable elastic elements for minimally invasive surgery", 2019 International Conference on Robotics and Automation (ICRA), Pages 2663-2669, IEEE, 2019.

14. Singh, D., Tawk, C., Mutlu, R., Sariyildiz, E., Sencadas, V., Alici, G., “A 3D Printed Soft Force Sensor for Soft Haptics", in 2020 3rd IEEE International Conference on Soft Robotics (RoboSoft), Pages 458-463, IEEE, 2020.

15. Zhu, Y., Zhang, J., Wu, Q., Chen, M., Huang, G., Zheng, J., Wu, J., “Three-Dimensional Programmable, Reconfigurable, and Recyclable Biomass Soft Actuators Enabled by Designing an Inverse Opal-Mimetic Structure with Exchangeable Interfacial Crosslinks”, ACS Applied Materials \& Interfaces, Vol. 12, Pages 15757-15764, 2020.

16. Wang, R., Huang, H., Xu, R., Li, K., Dai, J. S., "Design of a novel simulated 'soft' mechanical grasper", Mechanism and Machine Theory, Vol. 158, 2021.

17. Selvi, Ö., Telli, İ., Totuk, O. H., Mistıkoğlu, S., “3D Printing Soft Robots Using Low-Cost Consumer 3D Printers", in 4 th International Congress on 3D Printing (Additive Manufacturing) Technologies and Digital Industry 2019, K. Çetinkaya, B. Duman, K. Özsoy, K. Kayaalp, O. Oral, M. Aydın, Eds. Pages 1016-1021, Antalya, 2019

18. Donatelli, C. M., Serlin, Z. T., Echols-Jones, P., Scibelli, A. E., Cohen, A., Musca, J.-M., Rozen-Levy, S., Buckingham, D., White, R., Trimmer, B. A., "Soft foam robot with caterpillar-inspired gait regimes for terrestrial locomotion", in 2017 IEEE/RSJ International Conference on Intelligent Robots and Systems (IROS), Pages 476-481, IEEE, 2017.

19. Somm, L., Hahn, D., Kumar, N., Coros, S., "Expanding Foam as the Material for Fabrication, Prototyping and Experimental Assessment of Low-Cost Soft Robots with Embedded Sensing”, IEEE Robotics and Automation Letters, Vol. 4, Pages 761-768, 2019.

20. Yamada, Y., Nakamura, T., "Actuatable Flexible Large Structure Using a Laminated Foam-based Soft Actuator", 2020 IEEE/SICE International Symposium on System Integration (SII), Pages 74-79, IEEE, 2020.

21. Peters, J., Anvari, B., Chen, C., Lim, Z., Wurdemann, H. A., "Hybrid Fluidic Actuation for a Foam-Based Soft Actuator", 2020 IEEE/RSJ International Conference on Intelligent Robots and Systems (IROS), Pages 8701-8708, IEEE, 2020.

22. Yamada, Y., "Feasibility Study on Botanical Robotics: Ophiocordyceps-like Biodegradable Laminated Foam-Based Soft Actuators with Germination Ability", IEEE Robotics and Automation Letters, Vol. 6, Pages 3777-3784, 2021.

23. Kastor, N., Mukherjee, R., Cohen, E., Vikas, V., Trimmer, B. A., White, R. D., "Design and Manufacturing of Tendon-Driven Soft Foam Robots", Robotica, Vol. 38, Pages 88-105, 2020.

24. Mac Murray, B. C., An, X., Robinson, S. S., van Meerbeek, I. M., O’Brien, K. W., Zhao, H., Shepherd, R. 
F., "Poroelastic Foams for Simple Fabrication of Complex Soft Robots", Advanced Materials, Vol. 27, Pages 6334-6340, 2015.

25. Esser, F., Steger, T., Bach, D., Masselter, T., Speck, T., "Development of Novel Foam-Based Soft Robotic Ring Actuators for a Biomimetic Peristaltic Pumping System", Lecture Notes in Computer Science, Pages 138-147, Springer, Cham, 2017

26. Mac Murray, B. C., Futran, C. C., Lee, J., O’Brien, K. W., Amiri Moghadam, A. A., Mosadegh, B., Silberstein, M. N., Min, J. K., Shepherd, R. F., "Compliant Buckled Foam Actuators and Application in PatientSpecific Direct Cardiac Compression”, Soft Robotics, Vol. 5, Pages 99-108, 2018.

27. King, J. P., Bauer, D., Schlagenhauf, C., Chang, K.-H., Moro, D., Pollard, N., Coros, S., "Control of tendondriven soft foam robot hands", in 2018 IEEE-RAS 18th International Conference on Humanoid Robots (Humanoids), Pages, 1-9, IEEE, 2018.

28. Chen, Q., Zhao, J., Ren, J., Rong, L., Cao, P., Advincula, R. C., "3D Printed Multifunctional, Hyperelastic Silicone Rubber Foam”, Advanced Functional Materials, Vol. 29, 2019.

29. Futran, C. C., Ceron, S., Murray, B. C. Mac, Shepherd, R. F., Petersen, K. H., "Leveraging fluid resistance in soft robots", in 2018 IEEE International Conference on Soft Robotics (RoboSoft), Pages 473-478, IEEE, 2018.

30. Sutton, L., "The design of soft fluid filled actuators driven by conductive nylon", B.A.Sc Thesis, Simon Fraser University, Burnaby, 2019.

31. Liu, M., Wu, J., Gan, Y., Hanaor, D. A., Chen, C. Q., "Multiscale modeling of the effective elastic properties of fluid-filled porous materials", International Journal of Solids and Structures, Vol. 162, Pages 36-44, 2019.

32. Germain, L., Fuentes, C. A., van Vuure, A. W., des Rieux, A., Dupont-Gillain, C., "3D-printed biodegradable gyroid scaffolds for tissue engineering applications”, Materials \& Design, Vol. 151, Pages 113-122, 2018.

33. Castillo, E. H. C., Thomas, N., Al-Ketan, O., Rowshan, R., Abu Al-Rub, R. K., Nghiem, L. D., Vigneswaran, S., Arafat, H. A., Naidu, G., "3D printed spacers for organic fouling mitigation in membrane distillation", Journal of Membrane Science, Vol. 581, Pages 331-343, 2019.

34. Al-Shimmery, A., Mazinani, S., Flynn, J., Chew, J., Mattia, D., "3D printed porous contactors for enhanced oil droplet coalescence", Journal of Membrane Science, Vol. 590, 2019.

35. Abueidda, D. W., Elhebeary, M., Shiang, C.-S. (Andrew), Pang, S., Abu Al-Rub, R. K., Jasiuk, I. M., "Mechanical properties of 3D printed polymeric Gyroid cellular structures: Experimental and finite element study", Materials \& Design, Vol. 122, Pages 255-267, 2019.

36. Choi, J., Lee, D.-Y., Eo, J.-H., Park, Y.-J., Cho, K.-J., "Tendon-Driven Jamming Mechanism for Configurable Variable Stiffness", Soft Robotics, Vol. 8, Pages 109-118. 2021.

37. Zhou, J., Chen, Y., Hu, Y., Wang, Z., Li, Y., Gu, G., Liu, Y., "Adaptive Variable Stiffness Particle Phalange for Robust and Durable Robotic Grasping", Soft Robotics, Vol. 7, Pages 743-757, 2020.

38. Brancadoro, M., Manti, M., Tognarelli, S., Cianchetti, M., "Preliminary experimental study on variable stiffness structures based on fiber jamming for soft robots", 2018 IEEE International Conference on Soft Robotics (RoboSoft), Pages 258-263, IEEE, 2018.

39. Jiang, Y., Chen, D., Liu, C., Li, J., "Chain-Like Granular Jamming: A Novel Stiffness-Programmable Mechanism for Soft Robotics", Soft Robotics, Vol. 6, Pages 118-132, 2019.

40. Miller-Jackson, T., Sun, Y., Natividad, R., Yeow, C. H., "Tubular Jamming: A Variable Stiffening Method Toward High-Force Applications with Soft Robotic Components", Soft Robotics, Vol. 6, Pages 468-482, 2019.

41. Zhang, Y., Zhang, N., Hingorani, H., Ding, N., Wang, D., Yuan, C., Zhang, B., Gu, G., Ge, Q., "FastResponse, Stiffness-Tunable Soft Actuator by Hybrid Multimaterial 3D Printing", Advanced Functional Materials, Vol. 29, 2019.

42. Manti, M., Cacucciolo, V., Cianchetti, M., "Stiffening in Soft Robotics: A Review of the State of the Art", IEEE Robotics \& Automation Magazine, Vol. 23, Pages 93-106, 2016.

43. Xie, M., Zhu, M., Yang, Z., Okada, S., Kawamura, S., "Flexible self-powered multifunctional sensor for stiffness-tunable soft robotic gripper by multimaterial 3D printing", Nano Energy, Vol. 79, 2021.

44. Giannaccini, M. E., Xiang, C., Atyabi, A., Theodoridis, T., Nefti-Meziani, S., Davis, S., "Novel Design of a Soft Lightweight Pneumatic Continuum Robot Arm with Decoupled Variable Stiffness and Positioning", Soft Robotics, Vol. 5, Pages 54-70, 2018. 
45. Shahid, Z., Glatman, A. L., Ryu, S. C., "Design of a Soft Composite Finger with Adjustable Joint Stiffness", Soft Robotics, Vol. 6, Pages 722-732, 2019.

46. Zhu, M., Mori, Y., Wakayama, T., Wada, A., Kawamura, S., “A Fully Multi-Material Three-Dimensional Printed Soft Gripper with Variable Stiffness for Robust Grasping”, Soft Robotics, Vol. 6, Pages 507-519, 2019.

47. Wei, Y., Chen, Y., Ren, T., Chen, Q., Yan, C., Yang, Y., Li, Y., “A Novel, Variable Stiffness Robotic Gripper Based on Integrated Soft Actuating and Particle Jamming”, Soft Robotics, Vol. 3, Pages 134-143, 2016.

48. Santoso, J., Onal, C. D., " An Origami Continuum Robot Capable of Precise Motion Through Torsionally Stiff Body and Smooth Inverse Kinematics", Soft Robotics, 2020.

49. Zhang M., Zheng Y.P., Mak Arthur F.T., "Estimating the effective Young's modulus of soft tissues from indentation tests - nonlinear finite element analysis of effects of friction and large deformation", Medical Engineering \& Physics, Vol. 19, Issue 6, Pages 512-517, 1997.

50. Yamada, Y., Taro, N., "Actuatable flexible large structure using a laminated foam-based soft actuator", 2020 IEEE/SICE International Symposium on System Integration (SII). IEEE, Pages 74-79, 2020.

51. Chen, Q., Zhao, J., Ren, J., Rong, L., Cao, P. F., Advincula, R. C., “3D printed multifunctional, hyperelastic silicone rubber foam”, Advanced Functional Materials, Vol. 29, Issue 23, Pages 1900469, 2019

52. Argiolas, A., Mac Murray, B. C., Van Meerbeek, I., Whitehead, J., Sinibaldi, E., Mazzolai, B., Shepherd, R. F., "Sculpting soft machines", Soft Robotics, Vol. 3, Issue 3, Pages 101-108, 2016. 